\title{
HORTICULTURAL SCIENCE AT THE UNIVERSITY OF READING
}

$\mathrm{T}$ HE diamond jubilee of the Horticultural Education Association was marked by a conference at the Univorsity of Reading during September 6-9. The object of the conforence indicated by the theme, "Horticultural Science at the University of Reading", was to bring together contributions from a number of the branchos of seience that find a meeting point in the technology of horticulture. It was part of the success of the conference that it dirocted attention to the importance of border-line research between disciplines and to the desirability of combining pure and applied research.

Contributions from the Department of Horticulture were concerned with plant physiology and plant protection. Prof. O. V. S. Heath discussed methods of measuring stomatal aperture and pointed to the importance of a knowledgo of stomatal physiology in attempts to control water loss from crop plants. Dr. H. Meidner demonstrated a portable and rolatively cheap instrument for measuring the water content of soils by determination of their heat conductivity. One of the main advantages of the method was that the probo omployed, unlike the porous block used in othor techniques of soil moisture determination, did not havo to equilibrate with water in the soil.

Papers by Dr. D. Vinco and Dr. G. P. Harris were concernod with the photoperiodic control of flowering in long-day plants. Dr. Vince described experiments with different strains and species of Lolium that demonstrated a changing sensitivity to red and far-red radiation during a 16-h night. It appeared that in order to produce a maximum promotion of flowering by interruption of the night with red light, the timing of the interruption had to be varied according to the species or strain of Lolium used. The potentialities of detailed investigations of the photoperiodic responses of plants of horticultural importance were undorlined in the paper by Dr. Harris on flowering in the glasshouse carnation. Out of a number of photoperiodic treatments tested, the use of lighting from tungsten-filament bulbs throughout the night was found to be most effective in promoting flowering under winter conditions. Applications of this observation to commercial practice were discussed. Dr. H. F. van Emden bridged the gap between plant physiology and entomology in a discussion of plant-insect relations. Results were presented indicating the role of the nitrogen status of the plant and particularly the solublenutritional content in controlling rates of aphid multiplication.

The Agricultural Research Council Unit of Flower Crop Physiology, which, under the direction of Prof. O. V. S.
Heath, is attached to the Department of Horticulturo, was represented both in a comprehensive demonstration of equipment and in a paper read by Dr. A. P. Hughes. The main item of equipment in the Unit is 9 (later to bo 12) growth cabinets designed by the National Institute of Agricultural Engineering and housed in a special hall with controlled ventilation. Dr. Hughes doseribed the use of this equipment to investigate intoractions of light intensity, temperature and carbon-dioxide concentration. He also presented results of experiments demonstrating effects of photoperiodic treatmonts on leaf expansion in a variety of plants and discussed the use of such treatments under conditions where light intensities are limiting to growth in dry weight.

In a contribution from the Department of Physiological Chemistry, Dr. K. A. Hassall discussed problems encountered in the use of crop protection chemicals including questions of toxicity, persistence and selectivity. Experimental rosults showed how the persistence and effectivoness of a pre-emergence weed-killer could vary with the amount of rain falling after application.

From the Department of Agricultural Botany there were papers on physiological ecology and plant breeding and genetics. Prof. A. H. Bunting doscribed work on the water relations of plants growing on soils of the chalk downs near Reading and demonstrated the capacity of the chalk to retain water by reference to its $p \mathrm{~F}$-moisture content curve. The pore size distribution derived from this curve was shown to be similar to a distribution based on direct measurements of pore sizes in electronmicrographs. Dr. J. K. Jones and Mr. G. D. Rowley in contributions concerned with plant breeding both emphasized the value of using wild species as sources of genetic variation. Dr. Jones presented evidence that the sets of chromosomes in all species of strawberries were homologous, that it was possible to produce many inter-specific hybrids and to induce polyploidy and therefore to use most, if not all, of the species in breeding. Mr. Rowley showed how the derivation of cultivars of rose could be traced by crossing supposed parent species and underlined the importance of making provision for the conservation of species and cultivars that might not be of immediate. commereial valuo.

This report indicates the varied nature of the papers presentod; but the contributions had in common an immodiate or potential value to horticulture. The conference provided members with the opportunity to examine the role of the University in the development of this subject.
G. P. Harris

\section{THE WORLD HEALTH ORGANIZATION, 1964}

\begin{abstract}
A
REMINDER that the control of communicable discases is "still the most important health challenge facing mankind" is given by Dr. M. G. Candau, directorgeneral of the World Health Organization, in his annual report for 1964 *.

It is not, therefore, surprising that, notwithstanding the new devolopments in the work of the World Health Organization, the chapter on communicable diseases remains the longest in the volume. While some diseases have doclined in public health and economic importance, others are still obstinate or present new problems.

* Official Records of the World Health Organization, No. 139: The Work of WHO. Annual Report of the Director-General to the World Health Organization: London: H.M.S.O., 1965.) 4 Sw. franes; $68.8 d . ; 1.25$ dollars.
\end{abstract}

Dr. Candau points to the increasing incidence of plague the heavy toll of cholera and smallpox, the continuing problems of malaria and tuberculosis, the upsurge in the incidence of syphilis and gonorrhoea. He lists, as the three main obstacles to effectivecon trol, lack of knowledge, insufficient international support for the Organization and financing of campaigns and, most formidable of all, lack of adequate health services in the countries most affected. Lasting success can be achievod only through the establishment of pormanent and effective hoalth services applying national health plans.

The experience of the Organization has shown that quick results cannot be expected; the countries most in need of assistance for national health planning are those where 
statistics are scanty, the shortage of trained staff acute, and where multiple health problems compete for priority. Nevertheless, Dr. Candau is able to report progress in comprehensive health planning in a number of countries, for example, Africa, Latin America, and Asia-the areas presenting the greatest problems.

In campaigns against many of the communicable diseases, the use of rosearch is a valuable adjunct to the work in the field. In its medical research programme, the Organization draws on the advice of leading experts in many special fields and now has the collaboration of laboratories in all parts of the world. The lists of the reference laboratories of the World Hoalth Organization and of scientific meetings during the year provide some indication of the scope of the programme. The research programme is by no means restricted to the communicable diseases. The report contains, for example, accounts of the present studies on cancer (including the possible relation between viruses and cancer), cardiovascular diseases, and human genetics - a new field of activity for the World Health Organization (see Nature, 208, 230; 1965). The importance of immunology is stressed, and achievements are mentioned in the Organization's relatively new programme of immunological research, particularly in relation to parasitic diseases - a hitherto largely unexplored area of immunization in which further research has been planned on the advice of an expert committee.

Other topics dealt with in the "General Review", constituting Part 1, include malaria eradication, environmental health, public health services, health protection and promotion, education and training, biology and pharmacology, health statistics, publications, information, and administration and finance. A final chapter outlines the work done in co-operation with the United Nations and related agencies, and with non-governmental organizations.

Part 2 deals with the health problems and programmes in each of the Organization's six regions-Africa, the Americas, south-east Asia, Europe, eastern Mediterranean and western Pacific. In each chapter, broad surveys of work in the region concerned are complemented by detailed descriptions of some of the typical projects in which the Organization is giving assistance. They include the preparation of a plan to be financed undor the United Nations Special Fund for the metropolitan area of Accra in Ghana; the improvement of nursing education and services in Guatemala; a project in south-east Asia to increase the local production of freeze-dricd smallpox vaccine, which is essential for the successful pursuit of the smallpox eradication campaign in tropical countries; malaria oradication in Pakistan; and, in the western Pacific region, the first regional conference of deans of medical schools. For the European region, one of the projects described is a symposium in Moscow on the toxicology of drugs and methods of ensuring the therapoutic safety of drugs.

The list of current projects contained in Part 3 is a reflexion of the Organization's varied activities and of their adaptation to the particular requirements of countrios in the various regions.

Information given in the annexes includes membership of the Organization, its executive board and expert committees, the budget, the secretariat, fellowships, awards under the medical research programme, and the reference centres.

\section{A COMPARISON OF EUROPEAN HEALTH SERVICES}

$\mathrm{A}^{\mathrm{L}}$ LL European countries have some form of administrative arrangements to deal with environmental health; for example, housing standards, water purity, sewage and refuse disposal, and food hygiene. Modern life has brought into prominence new environmental problems, largely arising from industrialization and urbanization. A special monograph on health services in Europe was prepared for the European Conference on Public Health Administration held by the World Health Organization Regional Office for Europe in Zagreb, Yugoslavia, in June 1964*.

Air pollution is one cause for concern. Already most industrialized European countries have special regulations giving local authorities a measure of control over industrial emissions. Czechoslovakia and other countries have established standards for the control of health hazards from this source, while in the Federal Republic of Germany there are trade regulations and a Civil Code. In the U.S.S.R., the Institute of General and Communal Hygiene of the Academy of Medicine is carrying out research on air pollution in the principal industrial centres. Maximum permissible concentrations for 20 pollutants commonly found in the air of industrial cities have already been worked out. In the United Kingdom, smokeless zones are being established under a Clean Air Act. In Spain, provision is made for air disinfection in hospitals and certain clinics, and special legislation has been created covering unhealthy and dangerous gases and smoke.

Noise, as a public health problem, is also being tackled. Bulgaria has imposed restrictions on it in industry and in transport. In Spain, what are called "silence campaigns"

* A limited number of copies of this document (reference Euro 268-4) are available to persons officially or professionally interested in the subject, on request from the World IIealth Organization Regional Office for Europe Copenhagen. have been carried out in the larger towns, where noise elimination is the concern of the municipal authorities and industrial boards. The U.S.S.R. has set up a Central State Health Inspectorate to deal with problems concerned with noise.

In many European countries, in accordance with the requirements of the International Commission on Radiological Protection, radiation hazards have been the subject of precautionary measures. In the United Kingdom, watch is kept on radioactivity in the air and in the soil by the Atomic Energy Authority in collaboration with the Medical and Agricultural Research Councils, and the Ministry of Housing and Local Government supervises the disposal of radioactive material. In Denmark, under an Act which has been in force since 1953, no radioactive material may be manufactured, owned or imported without special permission from the National Health Service, acting on behalf of the Ministry of the Interior; the Act lists safety precautions covering transport, storage, and use. Finland's Radiation Protection Act controls X-ray and other radiation installations, and Norway also has regulations covering the protection of personnel and the transport of radioactive material. Similar provisions exist in Czechoslovakia, Hungary, Ireland, Switzerland and Turkey. In the Federal Republic of Germany, the Max-Planck Institute of Biophysics carries out systematic investigations of radioactivity in ground water, rivers, and soil, and the meteorological stations make regular measurements of radioactivity in the atmosphere.

To-day, all countries in Europe have some arrangements for controlling the spread of infectious diseases, and the incidence of most of them has been on the wane for some time. Tuberculosis, however, still remains a cause for great concern. In the Federal Republic of Germany, several Länder have legislation providing for regular 